\title{
COMPUTER MODELING OF THE PROCESS OF OVERTURNING OF THE AUTOMOBILE
}

\author{
Edgar Sokolovskij \\ Dept of Transport Technological Equipment, Vilnius Gediminas Technical University, \\ Plytinès g. 27, LT-10105 Vilnius, Lithuania.E-mail: Edgar.Sokolovskij@ti.vtu.lt
}

Received 26 April 2006; accepted 4 December 2006

\begin{abstract}
The article deals with investigation of the possibilities of the program PC CRASH, meant for the computer modeling of the movement of vehicles. The computer modeling of the process of overturning of the automobile with the help of the program PC CRASH is introduced. The cross profile of the road, the height of the centre of gravity of the automobile and the other parameters are evaluated while modeling. The influence of the introduced parameters upon the computer modeling results is investigated. The possibilities of application of the computer modeling programs in the expert assessment of the traffic accidents are considered, the items on reliability of the results of modeling and the requirements, raised towards the experts, who work with such programs, are analyzed.
\end{abstract}

Keywords: automobile, overturning, computer modeling, traffic accident, examination.

\section{Introduction}

At present many computer programs for modeling of the movement of vehicles, which are usually meant for investigation of the traffic accidents, have been created in the world. These programs become more and more improved, seeking to evaluate as many factors as possible so that the results of the computer modeling are brought closer to the results of the real experiments.

Modeling of interaction of the wheel with the road is one of the most important components of the computer modeling. The main goal is to bring modeling of interaction of the wheel with the road as close to reality as possible. Firstly, it depends upon the selected mathematical model. The more factors are evaluated while creating the program or while improving it, the more precise results will be obtained while using this program. On the other hand, much depends upon the introduced parameters. While modeling the movement of the vehicle with the help of the computer program, many various data are introduced; for example, while modeling the process of braking, it is necessary to introduce the coefficient of cohesion (or the deceleration), loading of the automobile, the time of starting the drive of the braking system to operate, the time of increase of the deceleration, if necessary, the time of disbraking. There could be more parameters, if the automobile moves along different surfaces or when the movement of several automobiles is being modeled; for example, the mechanism of the traffic accident and the automobiles, which are moving according to different regimes. Non-precision of each introduced parameter increases the error of the results of modeling. Thus, it is very important to introduce as more precise parameters as possible [1-10].

\section{Computer modeling program PC CRASH}

The program PC CRASH is one of the computer programs, meant for modeling of the movement of vehicles $[11,12]$. New versions of this program are being created. The version 5.0 of the computer program PC CRASH will be investigated further on.

The coefficient of cohesion is set for the whole surface, afterwards the other coefficient of cohesion can be introduced for separate sections (Fig 1).

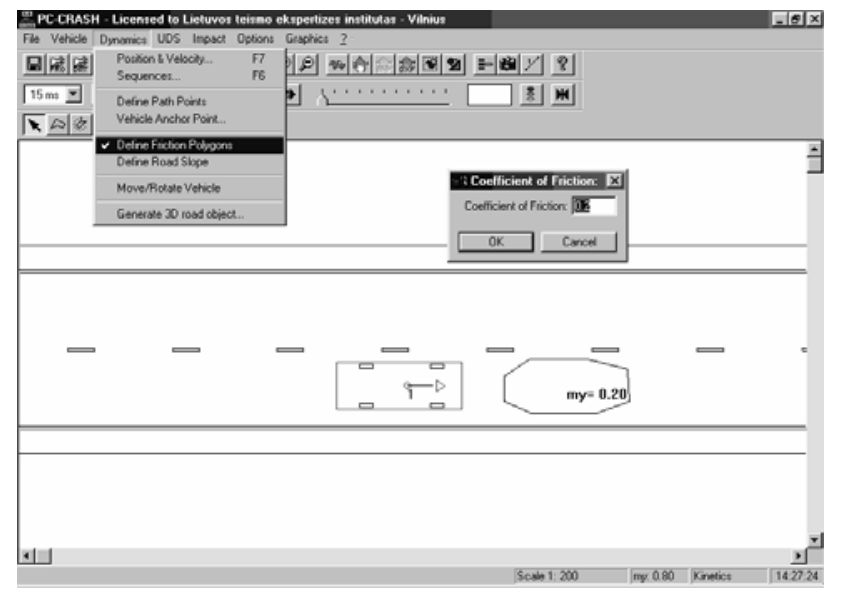

Fig 1. Introduction of a different coefficient of cohesion for a separate section of the road 
While modeling with the help of the computer program PC CRASH, firstly the definite model of the automobile, the movement of which is to be modeled, together with its appropriate characteristics is selected from the database (Fig 2).

Various regimes of the movement (braking, acceleration) of the automobiles, parameters of the deceleration and acceleration of the movement can be set.

There is a possibility to select and, while modeling, to evaluate such parameters of the automobile as the parameters of suspension, the degree of loading of the automobile, the type of the tires, distribution of the braking forces, etc. (Fig 3).
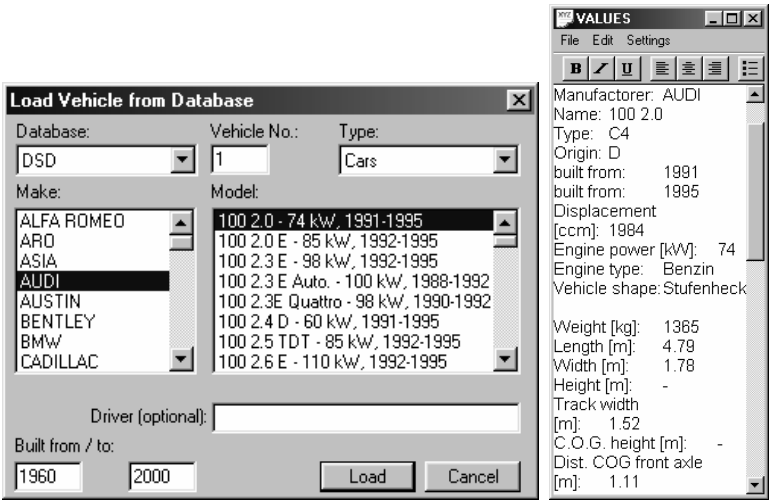

Fig 2. Selection of the model of the automobile from the database
After having selected the coefficient of cohesion, the program automatically selects the maximum possible deceleration of the automobile. It is possible, on the contrary, to introduce the value of deceleration, afterwards the coefficient of cohesion is to be recalculated (Fig 4). Besides, there is a possibility to introduce deceleration, as the function, from the speed. In this case, deceleration is modeled as the hyperbolic function, the parameters of which are calculated by introducing the values of deceleration, taking into consideration the speed of movement of the automobile, equal to 20 and $80 \mathrm{~km} / \mathrm{h}$. This model mostly suits for braking on a wet section of the road, when the speed is faster. However, it does not suit for modeling of the movement of the automobile after the crash, when dependence of the deceleration upon the speed may be of a completely different nature.

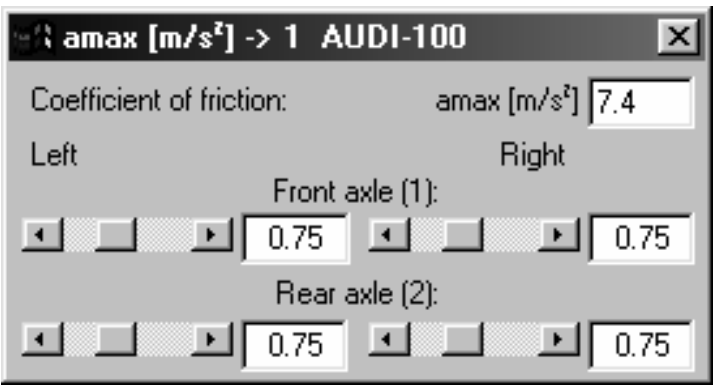

Fig 4. Introduction of the coefficient of cohesion and of deceleration depending upon the speed of movement of the automobile

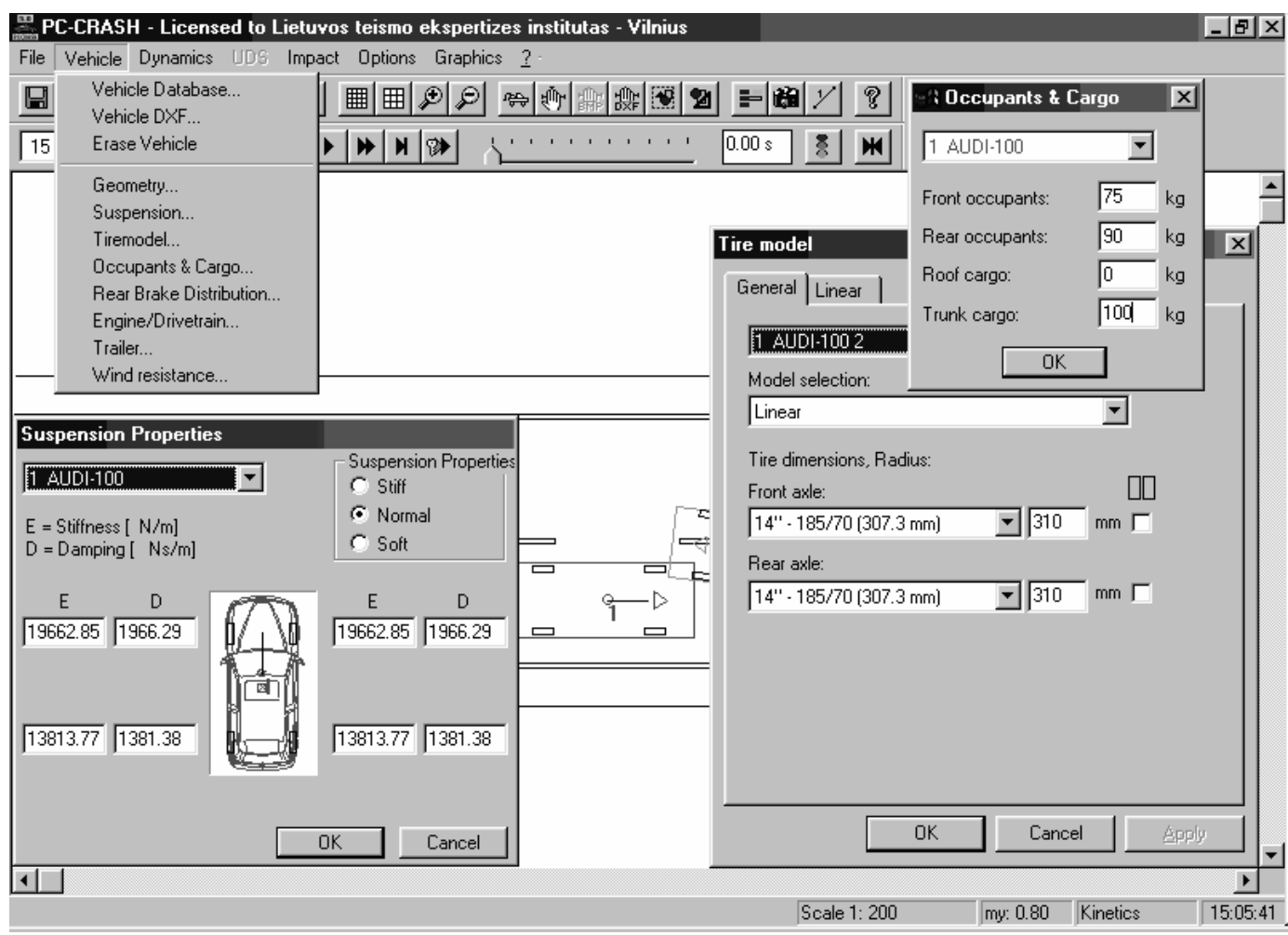

Fig 3. The general view of the screen while modeling with the help of the program PC CRASH (the parameters of the automobile, which may be selected, are viewed) 


\section{Modeling of overturning of the automobile}

In case of overturning of the automobile on its roof, the speed of its movement prior to its overturning can be calculated according to the following formula:

$$
v=\sqrt{26 g\left[\left(\sqrt{\left(\frac{B}{2}\right)^{2}+h^{2}}-h\right)+\left(\sqrt{\left(\frac{A}{2}\right)^{2}+\left(\frac{P}{2}\right)^{2}}-\frac{P}{2}\right)\right]},
$$

where $g$ is the acceleration of gravity $\left(9,81 \mathrm{~m} / \mathrm{s}^{2}\right) ; B$ is the width of the track of the automobile, $\mathrm{m} ; h$ is the height of the centre of gravity of the automobile, m; $A$ is the height of the automobile, $\mathrm{m} ; P$ is the width of the automobile, $\mathrm{m}$.

If, prior to overturning, the automobile had been sliding or, after overturning on its roof, had been overturning, this can be correspondingly evaluated by applying the formula. Besides, the expenditures of the kinetic power of the automobile for causing deformation of the automobile can be evaluated.

However, while modeling with the help of the computer program PC CRASH, it is possible not only to ascertain the speed of the automobile prior to its overturning, but to restore the movement of the automobile while overturning as well.

The possibility to model the movement of the automobile in the space (i.e. of the movement in the three planes), taking into consideration such parameters as the profile of the road, including the cross profile, location of the centre of gravity of the automobile, is one of the advantages of the program PC CRASH. It is very important because, without this possibility (for example, while modeling in the plane), it would be impossible to restore such a complex movement of the automobile as the process of overturning of the automobile. Figs 5-7 reflect the modeled overturning of the automobile, when the latter moves down from the slope of the road.

The following data were introduced:

Vehicle:

ROVER-620

Length, $\mathrm{m}$

4.65

Width, $m$

1.72

Height, $m$

1.38

C.G. height above ground, $\mathrm{m}$

0.50

Wheelbase, $\mathrm{m}$

2.72

Front track width, $\mathrm{m}$

1.48

Rear track width, $\mathrm{m}$

1.48

Mass (empty), kg

1255.00

Velocity, $\mathrm{km} / \mathrm{h}$

50.00

Mean brake acceleration, $\mathrm{m} / \mathrm{s}^{2} \quad 6.00$

Besides, the program PC CRASH provides the possibility to observe the view in the space (Figs 6-7).

In this case, while modeling the movement of the automobile according to the available data, the cross profile of the definite road section was introduced (Fig 8). Without having evaluated the latter, the automobile would be moving further on, without overturning.

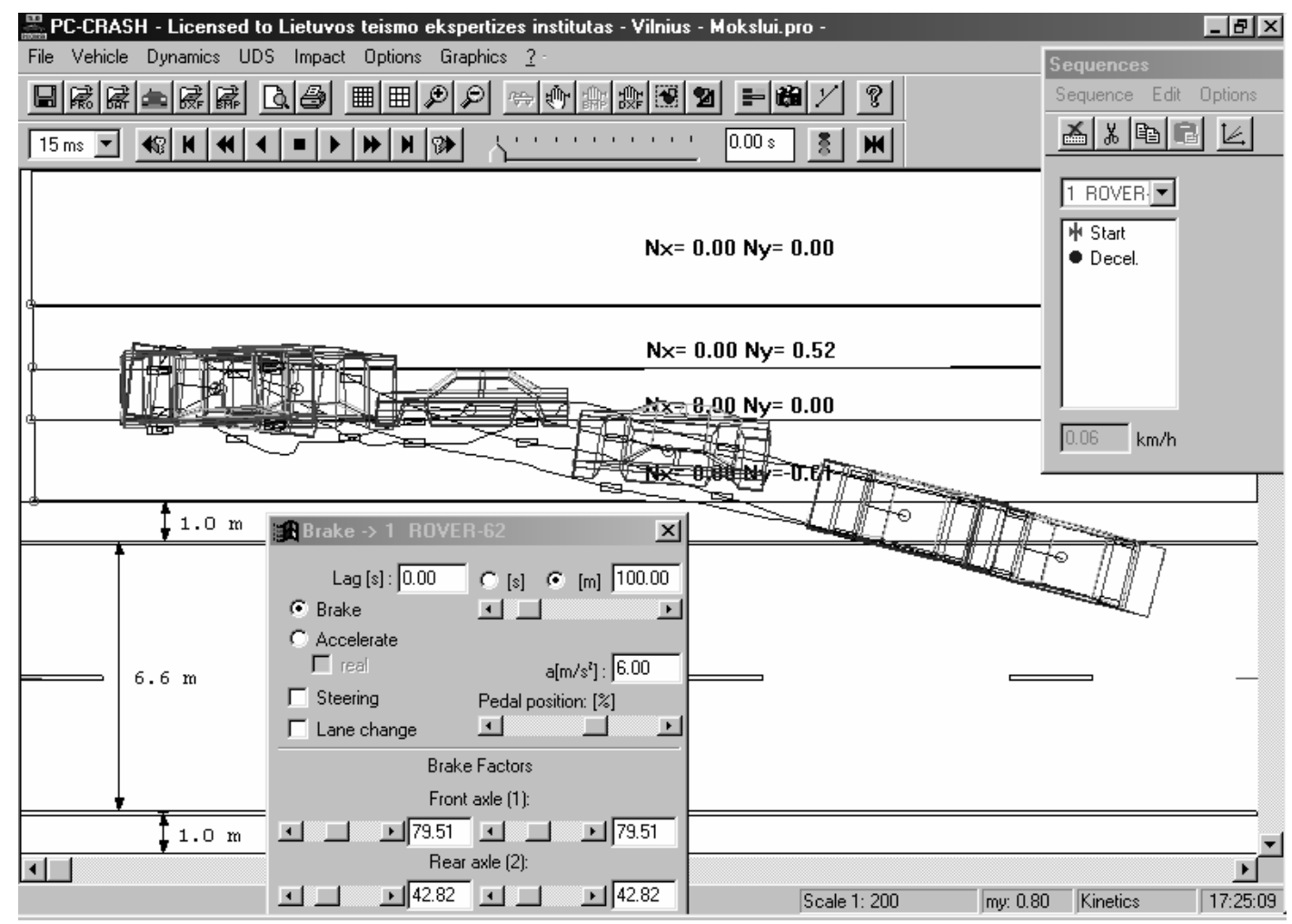

Fig 5. The view of overturning of the automobile from above 


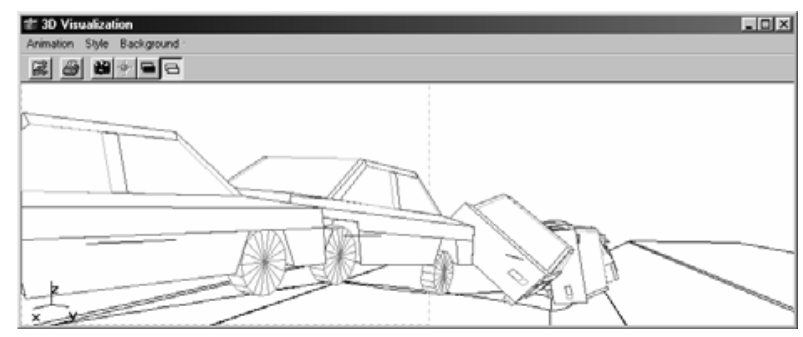

Fig 6. The view of overturning of the automobile in the space - from the back

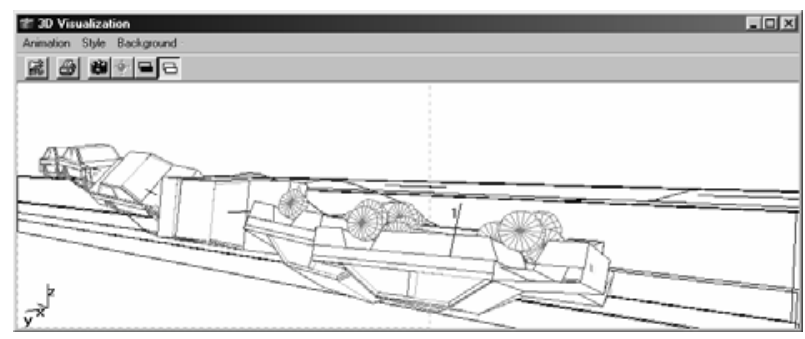

Fig 7. The view of overturning of the automobile in the space - from the front

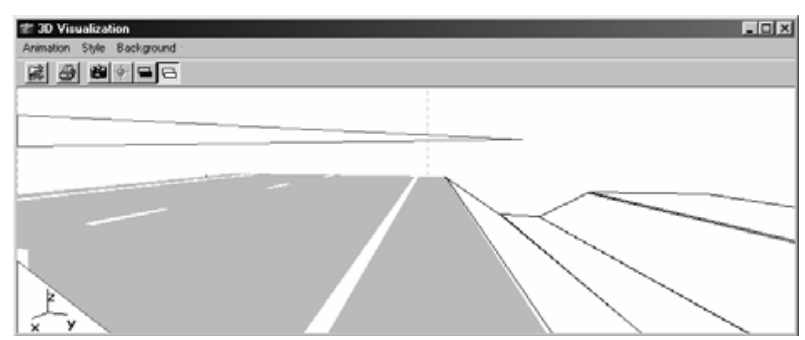

Fig 8. The cross profile of the road

The same pertains to the height of the centre of gravity of the automobile. For example, without having introduced the value of the height of the centre of gravity, the automobile will not overturn, even while moving according to the set trajectory, if the set cross slope of the road is introduced. After having carried out modeling and having accepted that the height of the centre of gravity of the automobile is equal to "zero", the obtained result shall look like in Fig 9. It is obvious that in this case the automobile will not overturn. In this case, all the same data were introduced, only the height of the centre of gravity is equal to "zero".

The computer modeling of overturning of the automobile, which was carried out, proves that the results of modeling depend upon the introduced parameters very much. In this case, having not evaluated the cross profile of the road, the height of the centre of gravity of the automobile and the other parameters, a completely different result may be obtained.

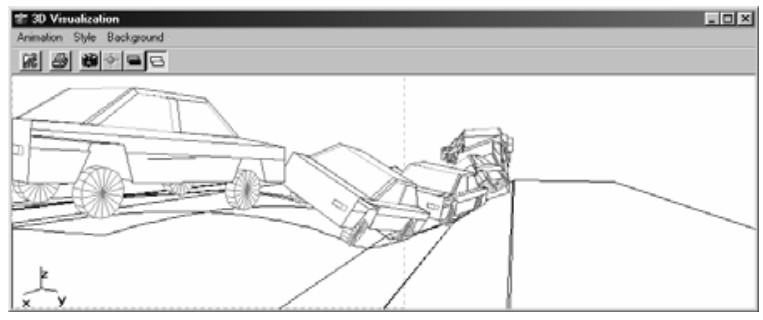

Fig 9. The movement of the automobile from the slope of the road, when the introduced height of the centre of gravity is equal to "zero"
Thus, seeking for reliability of the results of modeling of the course of the traffic accidents, it is very important that the experienced expert, having the appropriate qualification in introducing the necessary parameters and having enough skills of work with the computer modeling program, carries out the computer modeling. Only in this case the results of modeling will be reliable and can be used in the expert assessment of the traffic accidents.

\section{Conclusions}

1. Such programs of the computer modeling of the movement of vehicles as the program PC CRASH, make the work, carried out by the experts of investigation of the traffic accidents, easier, especially wishing to model several possible variants. The programs permit to evaluate various parameters, such as the parameters of the surface of the road (the parameters of cohesion), the parameters of the vehicle (the parameters of suspension, the degree of loading of the automobile, the type of the tires, distribution of the forces of braking, etc.) and provide the possibility to model various regimes of the movement of the automobile and such complex processes as overturning of the automobile.

2. The computer modeling of overturning of the automobile, which was carried out, proves that the results of modeling depend upon the introduced parameters very much. In this case, having not evaluated the cross profile of the road, the height of the centre of gravity of the automobile and the other parameters, a completely different result may be obtained.

3. Seeking for reliability of the results of modeling of the course of the traffic accidents, it is very important that the experienced expert, having the appropriate qualification in introducing the necessary parameters and having enough skills of work with the computer modeling program, carries out the computer modeling. Only in this case the results of modeling will be reliable and can be used in the expert assessment of the traffic accidents.

\section{References}

1. AHLGRIMM, J.; GRANDEL, J. Evaluation of traffic accident to cars with Antilock Brake System (ABS). Verkehrsunfall und Fahrzeugtechnik, 1997, No 3, p. 6774 (in German).

2. BOGDEVIČIUS, M.; PRENTKOVSKIS, O.; VLADIMIROV, O. Engineering solutions of traffic safety problems of road transport. Transport, 2004, Vol XIX, No 1, p. 43-50.

3. BOROVSKIJ, B. E. Traffic safety of automobile transport (Безопасность движения автомобильного транспорта). Leningrad, 1984. 304 p. (in Russian).

4. DANNER, M.; HALM, J. Technical analysis of road accidents (Technische Analyse von Verkehrsunfällen). Eurotax (International) AG CH-8808 pfäffikon, 1994. 570 p. (in German). 
5. ILARIONOV, V. A. Examination of road traffic accidents (Экспертиза дорожно-транспортных происшествий). Moscow: Transport, 1989. 254 p. (in Russian).

6. LANZENDOERFER, J.; SZCZEPANIAK, C.; SZOSLAND, A. Theory of automobile move (Teoria ruchu samochodu). Łódź: Wydawnictwo politechniki łódzkiej, 1988. 340 p. (in Polish).

7. LUKOŠEVIČIENĖ, O. The accident analysis and simulation (Autoịvykių analize ir modeliavimas. Monografija). Vilnius: Technika, 2001. 244 p. (in Lithuanian).

8. PANKIEWICZ, B.; LABA, K. Research of parameters having influence on traffic safety for some selected types of road vehicles. In Proceedings of the 5-th Symposium "Problems of reconstruction of road accidents", held in Zakopane on 24-26 October, 1996, p. 33-51 (in Polish).

9. PRENTKOVSKIS, O. Interaction between the vehicle and obstacles. Doctoral Dissertation (Automobilio sąveika su kliūtimis. Daktaro disertacija). Vilnius: VGTU, 2000. 117 p. (in Lithuanian).

10. SOKOLOVSKIJ, E. Investigation of interaction of the wheel with the road and its elements in the context of examination of traffic accidents. Doctoral Dissertation (Rato sąveikos su keliu ir jo elementais tyrimai eismo ivykiu ekspertizès kontekste. Daktaro disertacija). Vilnius: VGTU, 2004. 147 p. (in Lithuanian).

11. PC-CRASH. A Simulation program for vehicle accidents. Dr. Steffan Datentechnik, 1996. 202 p.

12. WACH, W. PC CRASH: A Simulation program for vehicle accidents (PC CRASH: Program do symulacji wypadków drogowych. Poradnik užytkownika). Cracow: Wydawnictwo IES, 2001. 353 p. (in Polish). 